\title{
In vitro performance of three combinations of spacers and pressurized metered dose inhalers for treatment in children
}

\author{
E. Berg*, J. Madsen $*$ H. Bisgaard +
}

In vitro performance of three combinations of spacers and pressurized metered dose inhalers for treatment in children. E. Berg, J. Madsen, H. Bisgaard. CERS Journals Ltd 1998. ABSTRACT: The performance of pressurized metered dose inhalers (pMDIs) and spacers in correct dose recommendations is important, but limited information on dose delivery and fine-particle dose from different combinations of spacers and pMDIs is available.

In this study, three combinations of spacers and pMDIs were investigated: NebuChamber ${ }^{\circledR}$ and AeroChamber ${ }^{\circledR}$ with budesonide pMDI and Babyhaler ${ }^{\circledR}$ with fluticasone propionate pMDI. Doses were withdrawn onto a filter either with a breathing simulator (dose to ventilator) or with constant flow (maximal dose). The fine-particle dose was assessed with a cascade impactor (Andersen Sampler). The effect of repeated use and cleaning of the spacers on the passive fallout of aerosol within the spacers was determined by evacuating the dose on a filter $2,5,10$ and $30 \mathrm{~s}$ after actuating the spray. The drugs were quantified by liquid chromatography.

The NebuChamber delivered the highest doses, both maximal dose and dose to ventilator. The recovered doses (mean $\pm \mathrm{sD}$ ) were $55 \pm 6 \%$ and $51 \pm 2 \%$, respectively, of the delivered dose from the pMDI. The corresponding results for the Babyhaler were $41 \pm 7 \%$ and $24 \pm 4 \%$ and for the Aerochamber $27 \pm 3 \%$ and $17 \pm 3 \%$. The passive fallout of aerosol, determined as half-life ( $t 1 / 2)$ was around $\sim 30 \mathrm{~s}$ for the NebuChamber, 9-15 $\mathrm{s}$ for the Babyhaler and $\sim 10 \mathrm{~s}$ for the AeroChamber.

The present study confirms that there are significant differences in dose output from different combinations of pressurized metered dose inhalers and spacers, with the NebuChamber giving the highest dose, both as delivered dose and in droplets $<4.7$ $\mu \mathrm{m}$. Interactions with the spacer material, dead space in the inspiratory line and entrainment of air during inhalation due to inefficient valve control could account for these differences.

Eur Respir J 1998; 12: 472-476.

Pressurized metered dose inhalers (pMDIs) with spacers adapted for use in young children have gained wide popularity. To provide optimal drug delivery, spacer design is critical [1]. The spacer causes important changes in the output in terms of total dose, as well as in terms of small-droplet mass. The mass of drug in small droplets of less than approximately $5 \mu \mathrm{m}$ is traditionally considered to be the dose fraction most likely to reflect the dose available to the lungs [2]. Effects, side-effects and cost-effectiveness are mainly related to the lung dose $[3,4]$ and are, therefore, strictly dependent on the combination of pMDI and spacer. The unity of pMDI plus spacer should consequently be stressed, and it would be desirable to relate dose recommendations to the output from the pMDI and spacer rather than simply to the nominal dose of the pMDI. However, until recently only limited information has been available on the small-droplet mass provided by different combinations of pMDI and spacer for young children.

The aim of the present study was to compare the delivered dose, as well as the output in small droplets, from three spacers developed for the treatment of young children: NebuChamber® ("Non-electrostatic metal spacer") Babyhaler® and AeroChamber ${ }^{\circledR}$.
*Pharmaceutical and Analytical R\&D, An-alytical Chemistry, Astra Draco AB, Lund, Sweden. Institute of Medical Physiology, University of Copenhagen, Copenhagen, Denmark. +Dept of Pediatrics, Pulmonary Service, Rigshospitalet, National University Hospital, Copenhagen, Denmark.

Correspondence: H. Bisgaard

Dept of Pediatrics

Pulmonary Service

Rigshospitalet

National University Hospital

DK-2100

Copenhagen, Denmark

Fax: 4535454812

Keywords: Budesonide children

electrostatic charge

fluticasone propionate

in vitro testing

spacer devices

Received: March 271997

Accepted after revision March 271998
Materials and methods

\section{Overall design}

In this study, which is divided into three parts, three combinations of spacers and pMDIs were investigated (NebuChamber and AeroChamber with budesonide pMDI and Babyhaler with fluticasone propionate pMDI): 1) doses were withdrawn onto a filter either with a breathing simulator (dose to ventilator) or with constant flow (maximal dose); 2) the fine-particle dose was assessed with a cascade impactor (Andersen Sampler); and 3) the effect of repeated use and cleaning of the spacers on the passive fallout of aerosol within the spacers was determined by evacuating the dose on a filter 2, 5, 10 and $30 \mathrm{~s}$ after actuating the spray

\section{Spacers}

In figure 1, schematic drawings are shown with arrows indicating the inhalation and exhalation paths. Dead space, discussed below, is a volume in the inspiratory line, common to both inhalation and exhalation. The drug-containing aerosol trapped in this volume will be lost during 
a)
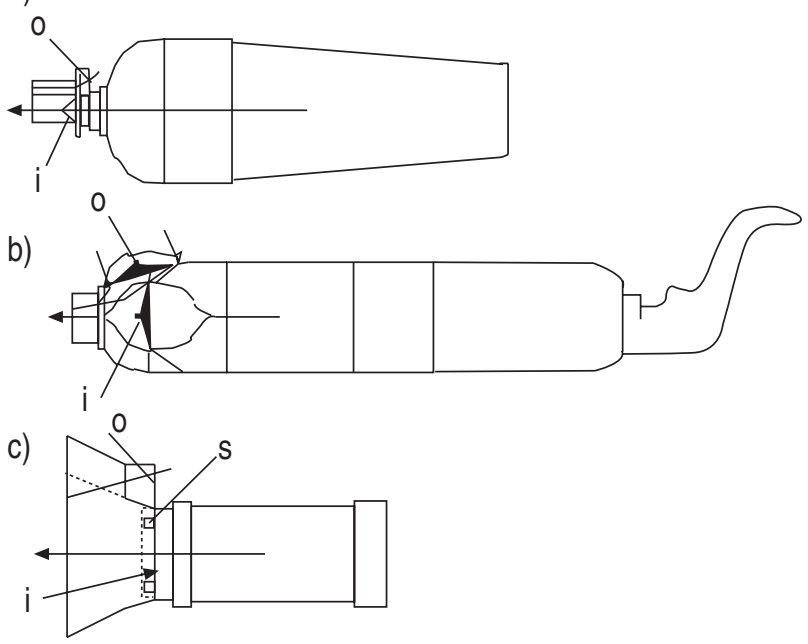

Fig. 1. - Schematic drawings of the spacers. a) NebuChamber; b) Babyhaler; c) AeroChamber. $\longleftarrow$ : inhalation;_— : exhalation; i: inlet valve; o: outlet valve; s: slits.

exhalation and the initial part of the next inhalation will contain exhaled air from the previous exhalation.

NebuChamber (Astra Draco AB, Lund, Sweden) is pearshaped and made of stainless steel. The volume is $250 \mathrm{~mL}$ and the valve system consists of two unidirectional valves orientated in opposite directions, i.e. no dead space is added to the inspiratory channel. The inlet valve is a duckbill valve passing the aerosol medially. The spacer inlet is specially designed to fit the Astra pMDIs.

Babyhaler (Glaxo, Ware, UK) is tube-shaped and made of polycarbonate. The volume is $350 \mathrm{~mL}$ and the inlet and outlet valves are separated by a $40 \mathrm{~mL}$ dead space. Both valves are hinged centrally, passing the aerosol at the valve periphery. The inlet is specially designed to fit the Glaxo pMDIs.

AeroChamber (Trudell Medicals, London, Ont, Canada) is tube-shaped and made of Ektar® plastic. The volume is $135 \mathrm{~mL}$. The inlet valve is a flap valve passing the aerosol through its centre. The outlet valve is placed in the facemask, assuring that no dead space is added to the inspiratory channel. Four slits between the facemask and spacer are open and may affect inspiration inflow. The inlet is designed for use with any pMDI.

\section{Pressurized metered dose inhalers}

Budesonide $200 \mu \mathrm{g}$ pMDI (Astra Draco AB) was used together with NebuChamber and AeroChamber. Fluticasone propionate $250 \mu \mathrm{g}$ pMDI (Glaxo) was used together with Babyhaler. The inhalers were shaken gently for $5 \mathrm{~s}$ before each actuation. Before testing, the pMDI were primed by firing waste puffs.

\section{Quantification of doses}

The drug amounts on the filters and on the impactor plates were dissolved in ethanol containing an internal standard (fluocinolone acetonide). Budesonide and flutica- sone propionate were quantified by reverse-phase liquid chroma-tography. The coefficient of variation $(\mathrm{CV} \%)$ of the me-thod was $<3 \%$.

\section{Setups}

Delivered dose and maximal dose were assayed by collecting the drug on a filter (VitalSigns, Totowa, NJ, USA) interposed between the device and an evacuation pump. More than $99 \%$ of the drug was trapped by the filter [5].

The dose to the ventilator, simulating the breathing of a young child, was assayed by collecting the drug on a filter (VitalSigns) interposed in the inspiratory line, in close proximity to the inspiratory valve. A Harvard Animal Respirator was used as the ventilator. The filter holder added $20 \mathrm{~mL}$ dead space to the system.

The particle-size distribution of the drug-containing aerosol cloud was analysed using an Andersen Sampler with an inlet throat consisting of a metal cylinder with a rightangled bend (US Pharmacopoeia), at a flow rate of 28 $\mathrm{L} \cdot \mathrm{min}^{-1}$. In this, size-distribution droplets $<4.7 \mu \mathrm{m}$ are referred to as small droplets or fine particles.

\section{Tests}

Delivered dose from the pMDI was measured by releasing one dose onto a filter while a constant flow of 30 $\mathrm{L} \cdot \mathrm{min}^{-1}$ was passed through the system. Dose outputs from four pMDI of budesonide and four pMDI of fluticasone propionate were measured five times each, making a total of 20 measurements of each drug. These same pMDIs were used for most of the subsequent measurements.

The dose to the ventilator from the pMDI and spacer was estimated by a ventilator set to a respiratory frequency of 20 breaths $\mathrm{min}^{-1}$, a tidal volume $(V \mathrm{~T})$ of $195 \mathrm{~mL}$, and a sinusoidal wave form with an inspiration to expiration ratio (I:E) of 1:2. The spacers had been treated before use by washing in a mild detergent, air-drying and subsequent priming with 15 puffs of spray at least $24 \mathrm{~h}$ before the test. Four pMDI and four spacers were tested using a Latin-square design. In total, 12 tests per spacer were made.

The maximal dose obtainable from the pMDI and spacer was estimated by evacuating the spacers by a flow of 30 $\mathrm{L} \cdot \mathrm{min}^{-1}$ for $10 \mathrm{~s}$, starting $2 \mathrm{~s}$ after actuation of the pMDI. The spacers were not connected to the filter during actuation. The same pMDI and spacers that were used in the ventilator test were tested. Four single doses from each spacer were analysed, i.e. a total of 16 measurements.

The particle-size distribution from the spacers was studied in spacers treated as described above, i.e. primed with 15 doses. Particle-size distribution was studied from three spacers with three pMDI.

The effect of repeated use of a spacer and subsequent cleaning on the aerosol half-life was assessed. The passive fallout was estimated by evacuating the aerosol from the spacers at 2, 5, 10 and $30 \mathrm{~s}$ after actuation of the spray. The half-life $(t 1 / 2)$ of the drug-containing droplets in the spacer was estimated from the semilogarithmic plot of the obtainable dose versus time. The $t 1 / 2$ for the aerosol cloud was determined: 1) in new spacers; 2) after priming with 15 puffs of pMDI the day before the test; 3 ) after washing and rinsing of spacers from (2); and 4) after washing in a $10 \%$ solution of detergent and rinsing in warm water. 
The dose estimates at each time point were based on 36 measurements from three spacers of each type.

The effect of repeated use of a pMDI on the delivered dose from a plastic spacer (Babyhaler) and a metal spacer (NebuChamber) was studied by repeatedly evacuating doses of fluticasone propionate or budesonide for 100 doses. The same new, untreated spacer was used throughout. Doses were obtained at $>1 \mathrm{~min}$ interval. In addition, this was repeated using two new untreated plastic spacers (Babyhaler) and two doses were delivered daily for one week.

\section{Statistical methods}

To reduce the influence from between-inhaler variation, the end-points (the maximal dose, the dose to ventilator and the dose in droplets $<2.1$ and $<4.7 \mu \mathrm{m}$ ) for each inhaler expressed are as a percentage of the dose delivered from that pMDI, as determined in the initial experiment.

The comparison of spacer brands with respect to maximal dose and dose to ventilator was made using normal approximation techniques allowing for possibly different standard deviations for the brands. A similar technique was used to compare these two end-points within the same spacer brand. Finally, the dose in droplets $<2.1$ and $<4.7$ $\mu \mathrm{m}$ was investigated using analysis of variance (ANOVA).

\section{Results}

\section{Delivered dose from the pressurized metered dose inhalers}

The mean delivered dose from budesonide pMDIs 200 $\mu \mathrm{g}$ was $89 \pm 4.8 \%$ (mean $\pm \mathrm{SD})$ of the nominal dose, while that from fluticasone propionate pMDIs $250 \mu \mathrm{g}$ was $92 \pm$ $4.4 \%$ of the nominal dose.

Dose to ventilator, maximal dose obtainable and particle size distribution

Results (means and $\mathrm{SD}$ ) for the maximal dose from pMDI and spacer, the dose from pMDI and spacer to ventilator and the particle-size distribution are presented in table 1 .

The maximal dose (at constant flow), as well as the dose obtained by a ventilator mimicking the breathing of a young child, was significantly higher from the NebuChamber than from the Babyhaler $(\mathrm{p}<0.001)$, which was higher than that provided by the AeroChamber $(\mathrm{p}<0.001)$. For both the Babyhaler and AeroChamber, the dose to ventilator was significantly lower than the maximal dose

Table 1. - Dose output from pressurized metered dose inhalers and spacers and particle-size distribution

\begin{tabular}{|c|c|c|c|c|c|}
\hline & \multicolumn{2}{|c|}{$\begin{array}{c}\text { Dose output } \\
\% \text { of delivered dose }\end{array}$} & \multicolumn{3}{|c|}{$\begin{array}{l}\text { Particle-size distribution } \\
\% \text { of maximal dose }\end{array}$} \\
\hline & $\begin{array}{l}\text { Maximal } \\
\text { dose }\end{array}$ & $\begin{array}{c}\text { Dose to } \\
\text { ventilator }\end{array}$ & $\begin{array}{c}\text { In } \\
\text { droplets } \\
<4.7 \mu \mathrm{m}\end{array}$ & $\begin{array}{l}\text { In } \\
\text { droplets } \\
<3.3 \mu \mathrm{m}\end{array}$ & $\begin{array}{c}\text { In } \\
\text { droplets } \\
<2.1 \mu \mathrm{m}\end{array}$ \\
\hline NebuChamber & $55 \pm 6$ & $51 \pm 2$ & $68 \pm 4$ & $36 \pm 5$ & $9 \pm 1$ \\
\hline Babyhal & $41 \pm 7$ & 24 & $95 \pm 1$ & $74 \pm$ & $35 \pm 1$ \\
\hline AeroChamber & $27 \pm 3$ & $17 \pm 3$ & $80 \pm 3$ & $44 \pm 3$ & $11 \pm 2$ \\
\hline
\end{tabular}

Values are mean \pm SD. $(p<0.002)$. This difference for the NebuChamber was not significant. The fine-particle fractions for all three spacers were significantly different $(\mathrm{p}<0.05)$.

Using the dose output and particle-size distribution from table 1, the fine-particle dose from pMDI and spacer could be calculated (table 2). The following assumption has been made: the particle size distribution for "dose to ventilator" is the same as for maximal dose.

Data from tables 1 and 2 are presented graphically in figure 2 .

Effect of repeated use of a spacer and subsequent cleaning on the aerosol half-life

Results for the estimated half-life for the drug-containing droplets in the spacer are presented in table 3.

The effect of repeated use of a pMDI on the delivered dose from a plastic spacer (Babyhaler) and a metal spacer (NebuChamber) is shown in figure 3.

Table 2. - Calculated fine-particle dose output (percentage of delivered dose)

\begin{tabular}{lcccrrrr}
\hline & \multicolumn{2}{c}{$\begin{array}{l}\text { In droplets } \\
<4.7 \mu \mathrm{m}\end{array}$} & \multicolumn{2}{c}{$\begin{array}{c}\text { In droplets } \\
<3.3 \mu \mathrm{m}\end{array}$} & \multicolumn{2}{c}{$\begin{array}{c}\text { In droplets } \\
<2.1 \mu \mathrm{m}\end{array}$} \\
\cline { 2 - 5 } \cline { 5 - 7 } & MD & DV & & MD & DV & MD & DV \\
\hline NebuChamber & 37 & 35 & 20 & 18 & 5 & 4 \\
Babyhaler & 39 & 22 & 31 & 18 & 14 & 8 \\
AeroChamber & 21 & 13 & 12 & 7 & 3 & 2 \\
\hline
\end{tabular}

MD: maximal dose; DV: dose to ventilator. a)

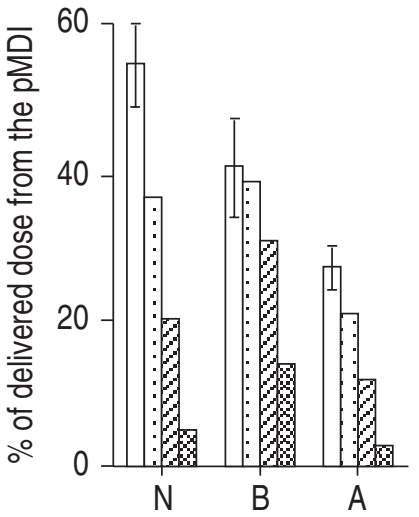

b)

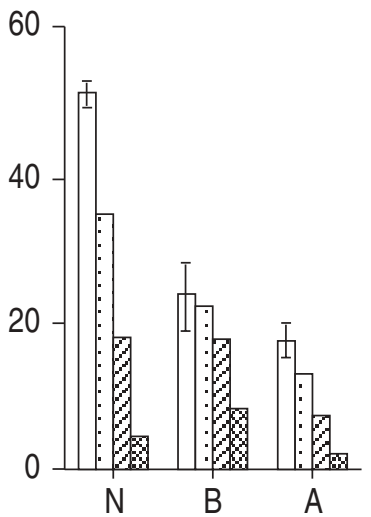

Fig. 2. - Summary of dose output ( $\square$ nean \pm sD) and calculated fineparticle dose; grouped by dose in droplets $<4.7 \mu \mathrm{m}$ ( $\quad$ B: $<3.3 \mu \mathrm{m}$ (

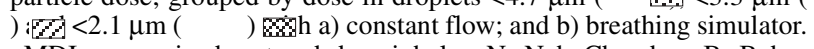
pMDI: pressurized metered dose inhaler; N: NebuChamber; B: Babyhaler; A: AeroChamber

Table 3. - Estimated half-life (s) for the drug-containing droplets in spacers treated in different ways

\begin{tabular}{lrccc}
\hline & \multicolumn{4}{c}{ Spacer condition } \\
\cline { 2 - 5 } & $\begin{array}{c}\text { Unused } \\
\text { spacer }\end{array}$ & $\begin{array}{c}\text { Primed } \\
\text { with } \\
15 \text { puffs }\end{array}$ & $\begin{array}{c}\text { Washing of } \\
\text { spacers* }\end{array}$ & $\begin{array}{c}\text { Washing in } \\
\text { concentrated } \\
\text { detergent }\end{array}$ \\
\hline NebuChamber & 28 & 29 & 29 & 31 \\
Babyhaler & 9 & 9 & 14 & 15 \\
AeroChamber & 9 & 9 & 12 & 10 \\
\hline
\end{tabular}

\footnotetext{
*: washing of spacers primed with 15 puffs.
} 


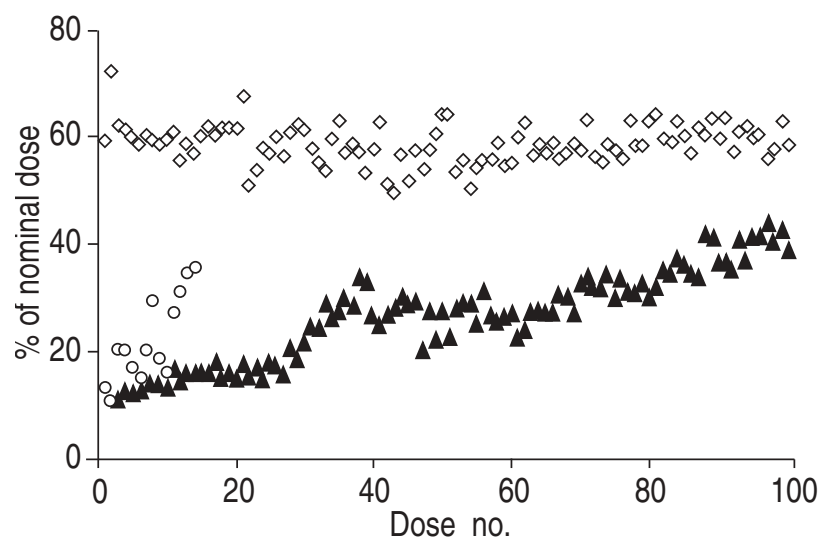

Fig. 3. - Effect of repeated use on the dose output (\% of nominal dose). : metakpacer (NebuChamber); $\boldsymbol{\Lambda}$ : plastic spacer (Babyhaler); $\bigcirc$ : babyhaler (two doses per day).

The dose from the metal spacer was consistent, about $60 \%$ of the nominal dose, throughout the 100 doses. The plastic spacer initially gave $15 \%$ of the nominal dose. During use, there was an increase up to $40 \%$ of the nominal dose. However, when two doses were taken daily, this increase occurred with fewer doses.

\section{Discussion}

The use of spacers in young children places special demands on the features of the spacers used, because of the unreliable cooperation of the children. Their breathing pattern is highly irregular. When the drug is administered to the child via a facemask, periods of apnoea are not uncommon. Ultimately, it may be necessary to administer the drug against the active resistance of the child. At the other extreme, the drug may have to be delivered to a sleeping child. Such circumstances impose a need for a short administration time and maximal concentration of respirable aerosol. In addition, to adapt to the irregular breathing pattern, a stable aerosol with a slow passive fallout of the aerosol is advantageous. Ventilation through the spacer has to be controlled by the inlet and outlet valves adapting to pressure changes, from the shallow breathing of the sleeping child producing pressure changes $<10 \mathrm{~Pa}$ to the crying baby creating pressures $>500 \mathrm{~Pa}$. Entrainment of air during inhalation will reduce the aerosol delivered in an unpredictable manner. Such entrainment may occur owing to inefficient valve control or leakage around the facemask.

\section{Clinical studies}

Three spacers have been introduced for the treatment of young children: Babyhaler, AeroChamber and NebuChamber. The efficiency of dose delivery from Babyhaler has been illustrated in clinical studies of the effect of salbutamol on lung function in young asthmatic children $[6,7]$. The doses administered were three to four times higher than the doses recommended for adults and the results could, therefore, hardly be taken as evidence of an efficient dose delivery. AeroChamber has been widely used in adults and older children and was adapted for use in young children by adding a facemask and, later, an expiratory valve. The efficacy of this adaptation was ascertained from a study showing improvement in symptom score in young asthmatic children from salbutamol pMDIs in unquoted doses [8]. NebuChamber was recently documented to deliver approximately $40 \%$ of the nominal dose of budesonide pMDIs to young children aged 6 months -7 yrs, independent of age, in a study of 128 asthmatic children [5]. However, only limited information has been available on the in vitro performance of these spacers with respect to dose delivery, small-particle delivery and availability of aerosol.

\section{In vitro performance}

The aim of this study was, therefore, to investigate the in vitro performance of three combinations of spacers and pMDI. The estimated fine-particle dose obtained by mimicking the breathing of a young child was significantly reduced compared with that from immediate evacuation of the spacer for the Babyhaler (22\% versus $39 \%$ ) and the AeroChamber (13\% versus $21 \%$ ), but not for the NebuChamber (35\% versus 37\%). This loss during a simulated breathing could be due to several factors. The filter holder used for collection added about $20 \mathrm{~mL}$ to the inspiratory line. This causes a $10 \%$ loss of aerosol contained in the $V \mathrm{~T}$ of $200 \mathrm{~mL}$ used by the ventilator. The dose collected from the NebuChamber by the ventilator was approximately $10 \%$ less than the maximal dose obtainable from evacuating the aerosol immediately, although this difference was not statistically significant. The Babyhaler has a valve system with an inherent dead space of $40 \mathrm{~mL}$ between the inlet and the outlet valve. Twenty per cent of the aerosol in the $V \mathrm{~T}$ of $200 \mathrm{~mL}$ is therefore caught in this dead space and subsequently exhaled. Further, the time needed to empty the relatively large volume of the spacer $(350 \mathrm{~mL})$ allows some time for passive fallout of the aerosol. Although the spacer volume is less than twice the $V$ T studied $(200 \mathrm{~mL})$, emptying is exponential and requires approximately 5-6 breaths to be complete, which takes $15-20 \mathrm{~s}$. The AeroChamber has four open slits between the facemask and spacer; part of the inhalation flow passes through these slits, prolonging the emptying of the spacer.

The described passive fallout also dramatically reduced the dose of fluticasone propionate available for inhalation from the Babyhaler at the beginning of the use of a new spacer. The effect was progressive through the use of 100 doses of fluticasone propionate. If the doses were administered at daily intervals, the priming effect was significantly better. The priming effect was further documented from the passive fallout $t 1 / 2$ of the aerosol remaining in the spacers, which was $10-15 \mathrm{~s}$ in the Babyhaler and about 10 $\mathrm{s}$ in AeroChamber. The aerosol within plastic spacers is prone to variable fall out, depending on the condition of the spacer, as it may vary depending on the use of sprays and washing procedures. The passive $t 1 / 2$ of a budesonide aerosol within the metal NebuChamber was 28-31 s, and was not affected by repeated use of the spray or washing with detergents. The rapid fallout of aerosol within plastic spacers is due to the electrostatically charged surfaces [9, 10]. Droplets generated from a pMDI carry charges on their surfaces and are, accordingly, attracted to the plastic surface. It is possible to pretreat the surface of the spacers with an antistatic agent or detergent to eliminate, at least 
partially, the effect of the electrostatic charges. However, it has not been documented how such treatment affects dose reproducibility and drug stability. The stability of various priming procedures is unknown and compliance with such repeated treatments is probably poor.

\section{Relative efficiency}

The calculated doses in droplets $<4.7 \mu \mathrm{m}$, using the simulated breathing, varied from $35 \%$ (NebuChamber) to $22 \%$ (Babyhaler) and 13\% (AeroChamber). The relative efficiency of the devices could be determined by relating the output from the Babyhaler and the AeroChamber to that from the NebuChamber: Babyhaler/NebuChamber= 0.63 and AeroChamber/NebuChamber $=0.37$. From such in vitro estimates, the relative efficiency of the NebuChamber, Babyhaler and the AeroChamber in delivering a fine-particle dose appears to be 1.0:0.6:0.4, respectively. These estimations are valid for optimal spacer performance, i.e. the plastic spacers were primed before testing. For unprimed plastic spacers, the differences from NebuChamber will be even more pronounced.

\section{Comparison in vitro and ex vivo}

In a recent ex vivo study in 42 young children $<3$ yrs old, the dose of budesonide trapped on a filter interposed between the facemask and the inlet valve was measured in a manner comparable to the methods used in the present in vitro study [5]. After adjusting for the differences in the fractions of small droplets, the doses obtained ex vivo as a percentage of the dose delivered from the pMDI were $29 \%$ from NebuChamber, 21\% from Babyhaler and 15\% from AeroChamber. Accordingly, an agreement was found between the results in the ex vivo study and the in vitro model simulating the breathing of young children. Both studies confirm the significant differences in dose output from the three spacers. It is certainly possible to increase the administered doses to obtain the desired effect. However, this will be at the expense of common sense and costeffectiveness and may increase the risk of side-effects [4]. The documented differences in dose output from the NebuChamber, Babyhaler and AeroChamber should be considered in any dose recommendation.

\section{Conclusion}

In conclusion, the present study confirmed that there were significant differences in dose output from different combinations of pressurized metered dose inhalers and spacers. The NebuChamber gave the highest dose, both as delivered dose and in droplets $<4.7 \mu \mathrm{m}$. Interactions with the spacer material, dead space in the inspiratory line and entrainment of air during inhalation due to inefficient valve control could account for these differences.

\section{References}

1. Bisgaard H. Delivery of inhaled medication to children. $J$ Asthma 1997; 34: 443-468.

2. Report of Task Group on Lung Dynamics to ICRP Committee 2, "Deposition and Retention Models for Internal Dosimetry of the Human Respiratory Tract". Health Phys 1966; 12: 173-208.

3. Lipworth BJ. New perspectives on inhaled drug delivery and systemic bioactivity (Editorial). Thorax 1995; 50: 105-110.

4. Bisgaard H. Drug delivery from inhaler devices (Editorial). BMJ 1996; 313: 895-896.

5. Bisgaard H, Anhøj J, Klug B, Berg E. A non-electrostatic spacer for aerosol delivery. Arch Dis Child 1995; 73: 226230.

6. Kraemer R, Frey U, Sommer W, Russi E. Short-term effect of albuterol, delivered via a new auxiliary device, in wheezy infants. Am Rev Respir Dis 1991; 144: 347-351.

7. Clarke JR, Aston H, Silverman M. Delivery of salbutamol by metered dose inhaler and valved spacer to wheezy infants: effect on bronchial responsiveness. Arch Dis Child 1993; 69: 125-129.

8. Conner WT, Dolovich MB, Frame RA, Newhouse MT. Reliable salbutamol administration in 6- to 36-month-old children by means of a metered dose inhaler and AeroChamber with mask. Ped Pulmonol 1989; 6: 263-267.

9. Barry PW, O'Callaghan C. The effect of delay, multiple actuations and spacer static charge on the in vitro delivery of budesonide from the Nebuhaler. Br J Clin Pharmacol 1995; 40: 76-78.

10. Bisgaard H. A metal aerosol holding chamber devised for young children with asthma. Eur Respir J 1995; 8: 856860. 